\title{
Serious Games to Improve Student Learning in Engineering Classes
}

\section{Mr. Pramod Rajan, Laboratory for Innovative Technology \& Engineering Education (LITEE)}

Pramod Rajan is in the doctoral program in the Department of Mechanical Engineering at Auburn University. He is a graduate research and teaching assistant. Rajan is currently working on developing serious games to improve student learning in engineering classes.

\section{Dr. P.K. Raju, Auburn University}

Dr. Raju is the Thomas Walter Distinguished professor of Mechanical Engineering at Auburn University. $\mathrm{He}$ is the co-founder and director of the NSF-funded Laboratory for Innovative Technology and Engineering Education (LITEE). LITEE has been recently recognized by the National Academy of Engineering as one of the twenty nine programs in the country that have successfully infused real world experiences into engineering undergraduate education. He is also the founder and director of the Auburn Engineering Technical Assistance Program (AETAP). Prior to coming to Auburn in 1984, Dr. Raju held faculty positions in several universities in India and visiting positions at the Catholic University of America, Purdue University, and the Technical University of Berlin. Dr. Raju received his Ph.D. from the Indian institute of Technology, Madras, in 1977. He has made significant research contributions in engineering education and innovations, acoustics, noise control, nondestructive evaluation and technology transfer, resulting in award-winning and significant breakthroughs. He has received a total of $\$ 12$ million in funding, including grants from industries, the United Nations, the National Science Foundation, NIST, NIH, EDA and other U.S. and international agencies. He has published 24 books, eight book chapters and 200 papers in journals and conference proceedings. He has received several awards for his teaching, research and outreach work from INEER, NASA, NSF, ASME, ASEE, Auburn University and others. He served as an United Nations and UNDP expert. Dr. Raju served as a World Bank lecturer at the National Aeronautical Laboratory, and the Bharat Earth Movers Ltd. Bangalore, India and the National Institutes of Technology, Trichy and Calicut. He has held Invited Professorships at the Université Bordeaux I, Talence, and Université Du Havre, Le Harve, France. He has been an invited/ keynote speaker at several national and international conferences. He is a fellow of the American Society for Engineering Education, a fellow of the American Society of Mechanical Engineers, a fellow of the Institution of Engineers (India), and a fellow of the Acoustical Society of India. He is the editor-in-chief of the Journal of STEM Education: Innovations and Research.

\section{Dr. Chetan S Sankar, Auburn University College of Engineering}

Dr. Chetan S. Sankar is the College of Business Advisory Council Professor of Information Systems. He is a Co-Principal Investigator of four National Science Foundation grants worth more than a million dollars. The objective of these grants is to develop exceptional instructional materials that bring real-world issues into classrooms and to improve the higher-level cognitive skills of students. These instructional materials have been published and made available as nine textbooks that include multimedia CD-ROM supplements. The case studies and supplements bring alive the issues faced by Southern Company, Powertel, Chick-fil-A, AUCNET USA, and other companies into the classrooms. In addition to his current research and teaching interests, Dr. Sankar has published more than 100 papers in journals, book chapters, and conference proceedings. He has won many awards for research and teaching from the Society for Information Management, NEEDS and John Wiley and Sons, Decision Sciences Institute, American Society for Engineering Education - Southeastern Section, American Society for Mechanical Engineering, Auburn University, and the Project Management Institute. 


\title{
Serious Games to Improve Student Learning in Engineering Classes
}

\begin{abstract}
Experiential Learning has been proven to be effective in teaching engineering topics. Educational games, in particular, have the potential to address many systemic deficiencies for five reasons: massive reach, effective learning paradigms, enhanced brain chemistry, time on task and improved learning outcomes. ${ }^{1,2}$ Last fall, the American government awarded \$10.5 billion to the development of serious games for training purposes that result in better decision making. ${ }^{3}$ About 8,000 papers were identified that reported the positive impacts of games on users over the past 14 years. Of these, about 130 papers reported empirical evidence about impacts on learning and engagement. ${ }^{4}$ A serious game can be defined as a world where the students play simulated events using characters that interact with them, and, in turn, make them learn a concept much more thoroughly than what is possible in a classroom or in a lab session.
\end{abstract}

This paper describes a project where a university joined with a private company to teach the concept of design process by using a serious game. The paper provides details about the design and development of the serious game. The research model integrates organizational, engineering education and educational learning literature to research how game play interacts with learning styles, gender and race of the participants, thereby having the potential to act as facilitators to the learning process. The targeted student groups for this experiment will be freshmen engineering students at two universities. This paper describes a project where the concept of an engineering design process was taught using two engineering design learning modules, and evaluated using a control/experimental set up. In the control class, the students are exposed to a lecture about the engineering design process, an active learning exercise (Title: Statistics Applied to Data Analysis), and a pasta tower building activity. In the experimental set up, the students are exposed to a lecture about the engineering design process, a design simulation exercise (Serious game titled ' Engineering Heights: The Design Process in Action'), and a pasta tower building activity. External evaluators will use the same instruments and focus groups to collect both quantitative and qualitative assessment data for both sections. Analysis of the data from both a quantitative and qualitative perspective is expected to provide a set of findings. The results of this project can contribute to understanding whether serious games facilitate students' deep learning about the concept of design process.

\section{Introduction}

Engineering design is hard to learn and a harder skill to teach, and is defined as a systemic, intelligent process in which designers generate, evaluate and specify concepts for devices, systems or processes, whose form and function achieve clients' objectives or users' needs while satisfying a specified set of constraints ${ }^{5}$. It is also a part of systems engineering, which is another complex subject to understand.

Most mechanical engineering design courses require the students to work on over-simplified theoretical representations of real-world problems. This experience gives the students an in-depth understanding of the design principles, but they are not trained to link the theories to solving practical problems that occur in real life. Case studies have traditionally been used to show that 
real-world decisions should be made so that financial goals, technical needs, safety factors and credibility issues are simultaneously considered and weighed. ${ }^{6,7}$ Furthermore, Dym et al. (2005) ${ }^{5}$ talks about why case studies can be used effectively to teach engineering design principles.

For the past 10 years, the Laboratory for Innovative Technology and Engineering Education (LITEE) at Auburn University has been producing multi-media case studies in engineering, business and technology areas, and has been successfully implementing them at Auburn and several other universities. Students react positively to the use of these case studies in the classrooms. The STS-51L challenger case study, developed at the LITEE lab, is used in teaching the engineering design process to freshmen engineering students. After a series of evaluations on the case studies, the students felt that some of the case studies are over- whelming, present a lot of information, and need more audio/video to make it more interactive/immersive. So we decided to come up with a new innovative instructional material called Smart Scenarios. We worked with a learning solutions provider to develop the smart scenarios and tested them in classes. The pilot study conducted to verify feasibility of using smart scenarios in the classroom led us to develop the serious games to teach engineering concepts. In the next section, we will define what Smart Scenarios are and describe their development and classroom implementation.

\section{Smart Scenarios}

Smart Scenarios provide students with an immersive environment where they interact with a series of avatar characters as they work through a scenario. Like interactive scenarios, these are fully customizable, and can be crafted to your specific course topics and objects. However, the distinction is that Smart Scenarios are designed to help students integrate and assimilate information, rather than to set context for hands-on technical tasks. In Smart Scenarios, students interact with characters to gain information, validate ideas and advance their knowledge before being assessed. Smart Scenarios employ natural assessments, which deliver assessments in a variety of real world contexts, such as integrated discussions, email replies, presentations to colleagues, team meetings, creation of executive briefings, etc. Natural assessments allow students to demonstrate their command of the topics addressed, in the same way that they might in a real life situation, by articulating their knowledge to their virtual "boss", colleagues or others within the scenario. All information provided by the student in the assessment elements is captured and formatted for delivery to the course instructor for grading. A screen shot of a smart scenario is shown below in Figure 1. The STS-51L case study was chosen to be converted to an Engineering Design Smart Scenario.

The learning objectives for the Engineering Design Smart Scenario were:

- Understand the eight steps of engineering design: problem definition, concept formation, concept evaluation, concept evaluation, detailed design, prototyping, testing, and send to production.

- Define each step.

- Illustrate each step from the Challenger STS 51-L case study.

- Analyze data presented that shows test results of all shuttle launches before STS 51-L with temperature and number of failures in O-ring. Different graphs are presented in the Smart Scenario: Figure 2a only uses failures with temperature and it is difficult to 
correlate temperature and O-ring erosion from this information because of the severe erosion at 75 degrees (STS 61A). Figure 2b provides a complete plot of all failures with temperatures and uses a logistic regression. This shows that the probability of failure is close to 1 at temperatures below 35 degrees Fahrenheit.

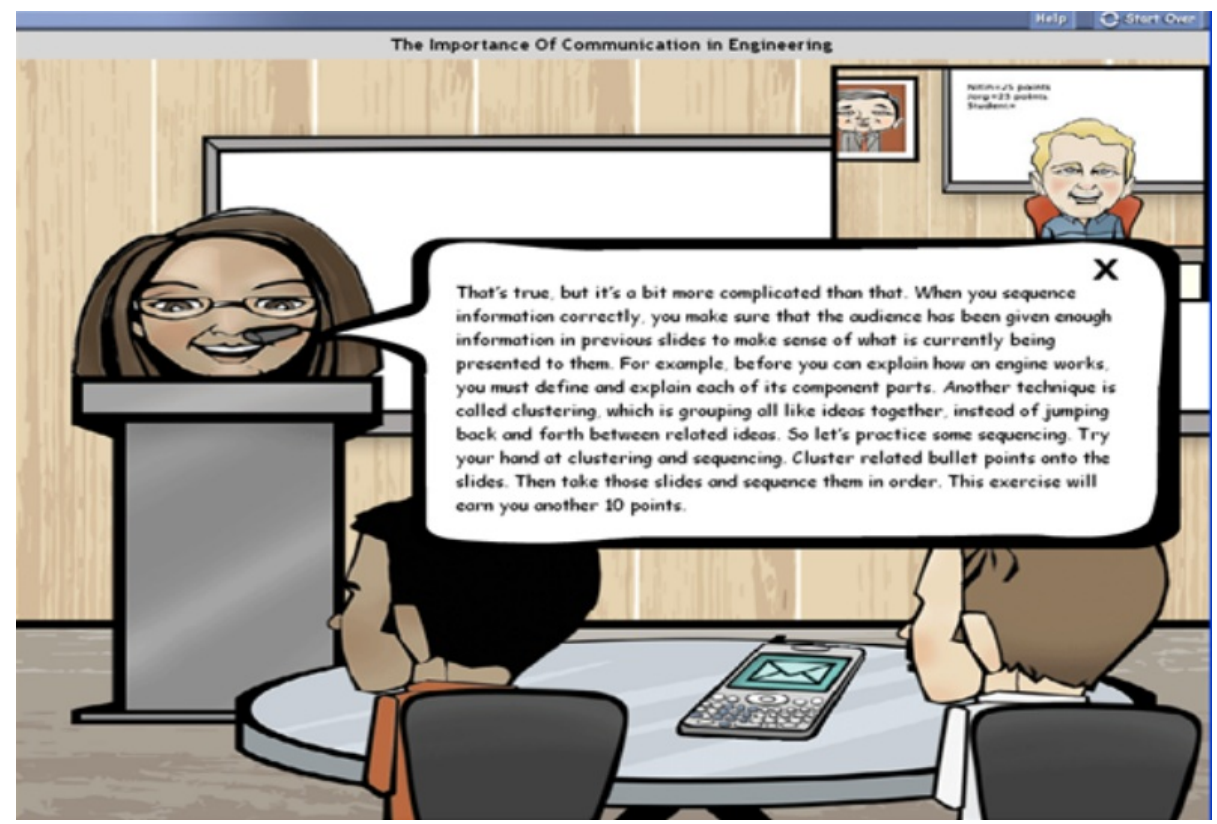

Figure 1.Screenshot of Engineering Design Smart Scenario
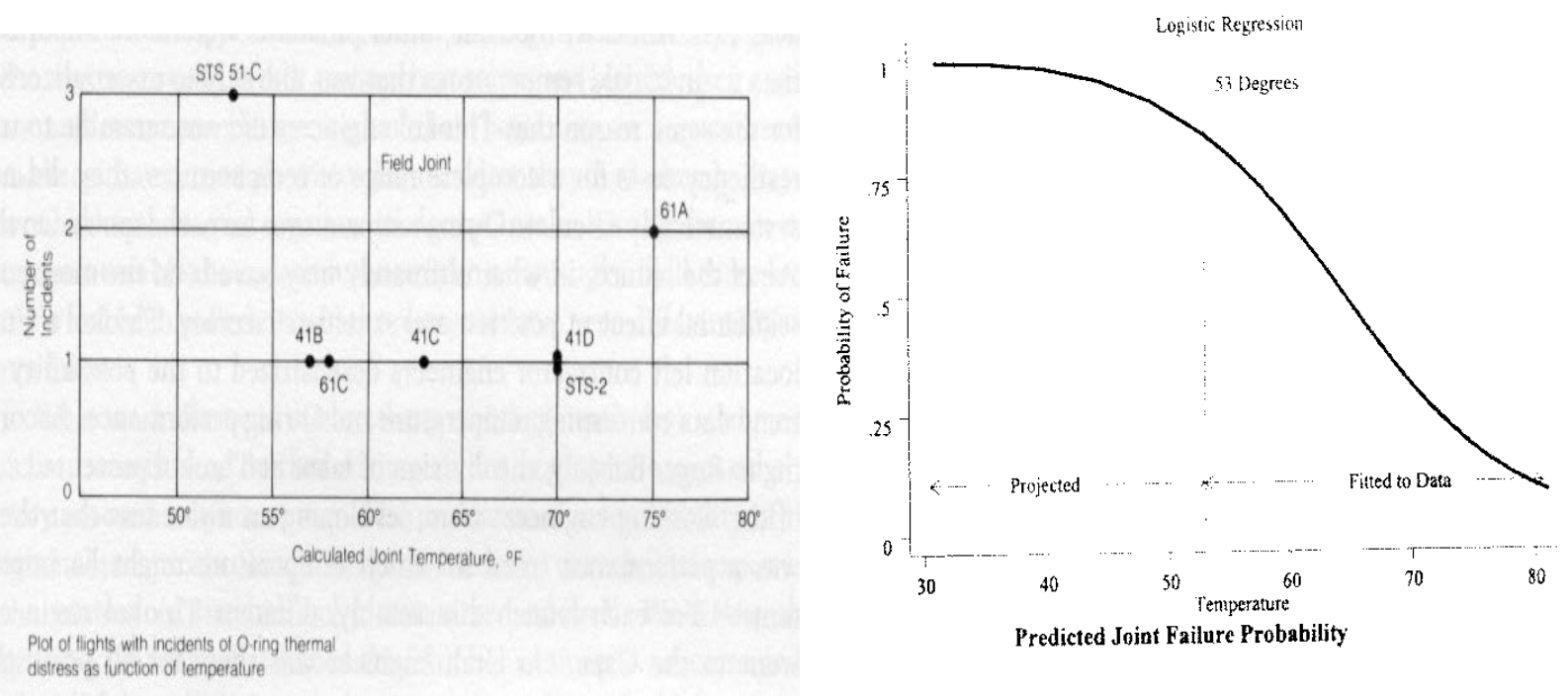

Figures 2a and 2b: Different interpretation of data 


\section{Sample}

This pilot version of the Smart Scenario was tested in an Introduction to Engineering course at Auburn University during November 2010. Overall, 52 students worked with the Engineering Design Smart Scenario, of which 45 were male and seven were female.

\section{$\underline{\text { Results }}$}

The survey was developed by a team of evaluators. Seventy percent of the students expressed an interest in working with such an instructional material in the future. Sixty eight percent of the 52 students who used the design Smart Scenario said that they read through the required material deeply, 35 percent said that it improved their thinking skills, and 27 percent said that they became more conversant with the technical information. Eighty percent of the students perceived this to be a different method of learning and 30 percent found it to be realistic. Forty percent of the students said that the Smart Scenario was an innovative method to learn engineering design and 60 percent of the students preferred the gaming aspect that was included in the pilot study. Sixty five percent of the students said that the Smart Scenario could be easier to navigate and needs to include video and audio material. Forty four percent wanted the scenario to be made more like a game and 35 percent expressed the need to simplify the user interface. Thirty percent of the students were willing to pay extra fees to work with such an instructional material.

Two instructors who used the Smart Scenarios commented:

"I think they are very well created and designed. Overall, I think this is actually another huge improvement to the case study. The biggest advantage of this gaming style learning is that the students had to keep their attention on all materials since there are multiple mini tests/quizzes. The questions are challenging enough for me. The single and multiple questions are nice and balanced.

The students appeared to be genuinely interested in the Toolwire Smart Scenario. While there were a few issues brought up by multiple students, I believe the interactive computer format provided deeper engagement in the material than that of a lecture session.

\section{Serious Games}

Based on the feedback we have received from the pilot study with smart scenarios, we realize that additional steps were needed to create a learning game that fully met the students' needs. Key elements that emerged as part of this pilot suggest that future development should reduce complexity and length, implement both audio and video, move away from cartoon depiction, and enhance gaming functionality and the multi-pathed nature of the game. While we are pleased with the product used for this pilot, this feedback is in line with our expectations and will serve to guide us in the creation of the next version of these learning games. In the next section we talk about the serious games, the need for serious gaming to teach design, its implementation, and the research model used to evaluate the serious game. 


\section{$\underline{\text { Introduction }}$}

$\mathrm{Abt}^{8}$ (1987) described serious games as having an, "explicit and carefully thought-out educational purpose”:

"Games may be played seriously or casually. We are concerned with serious games in the sense that these games have an explicit and carefully thought-out educational purpose and are not intended to be played primarily for amusement. This does not mean that serious games are not, or should not be, entertaining."

Serious games are games, or game-like interactive systems, developed with game technology and design principles for a primary purpose other than pure entertainment. There is still little solid, irrefutable evidence of the effectiveness of games in the classroom and how serious games compare to more traditional methods. Research is still in the early stages, but some of the research shows real promise and demonstrates the potential benefits of the games. Serious games can be used for education at all levels, from preschool and elementary school, through middle school and high school, into colleges and universities, and even into the job market. One game does not have to support all of these levels, but some might be able to. As Prensky ${ }^{9}$ (2001) pointed out, games are good for two things. First, there are particular techniques or attributes of games that can help students learn complex material faster, and understand that material better. Second, games can increase the level of engagement of the trainees so that they want to play the game and they want to learn how to successfully complete the game.

\section{Need for serious gaming}

Educational gaming addresses ABET criteria by engaging students in the learning process while meeting the following learning objectives

3i: Recognition of the need for lifelong learning

3e: Ability to solve and define problems

3h: Understand impact of engineering solutions in global and societal context

A search of the Chronicle of Higher Education archives showed over 100 articles that mentioned "game-based learning" or "games in the classroom" during the past year. Past literature shows that design cannot be taught sufficiently in lectures alone There needs to be a more active learning experience. Hernandez and Davila ${ }^{10}$ (2010) discuss the need to develop proper design skills in the student prior to the project experience, and stress the need to use educational theories (teaching styles, learning styles, etc.) to develop these skills. So, we decided to expose the students to traditional lecture, active learning exercises and a serious game, to evaluate the learning outcomes.

\section{Engineering Design Serious Game}

The serious game was designed to teach the engineering design process to the students. The engineering design process used in development of this game is shown in Figure 3. 


\section{Elements of the Design Process:}

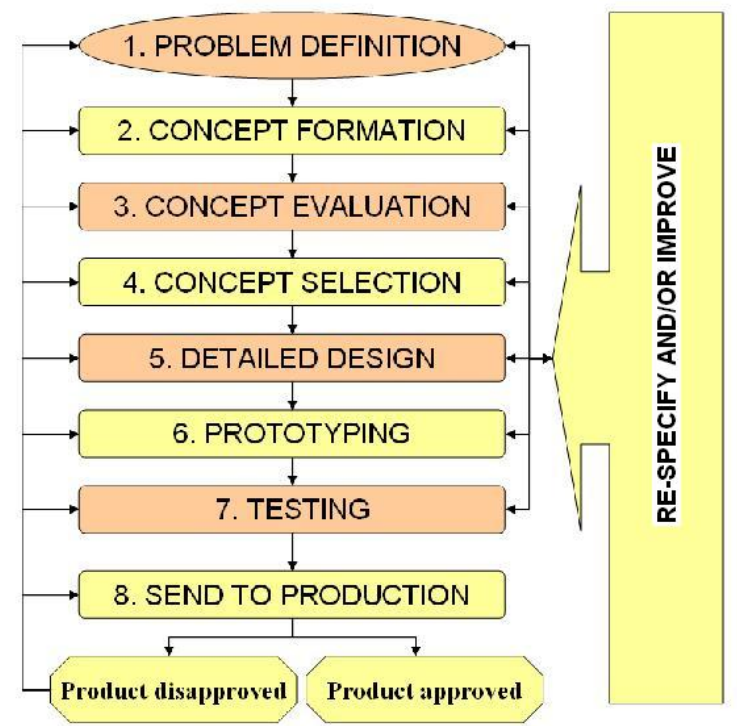

Figure 3. Design process used in the game

The design process chart is inspired from the Pahl and Beitz (2007) model of the design process. ${ }^{11}$ We focus on the first seven steps of the design process in the game. The game is titled 'Engineering Heights: The Design Process in Action'. A screen shot of the first screen of the game is shown in Figure 4.

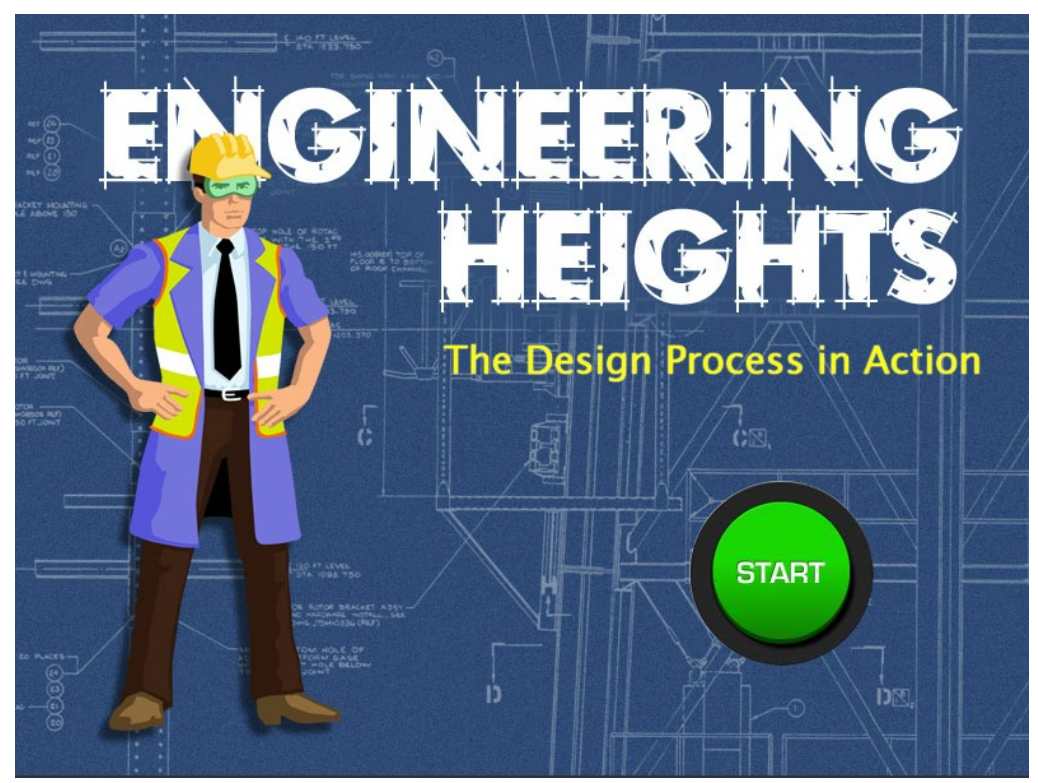

Figure 4. Screen shot of the design serious game 
We decided to use the example of building a structure to support a railroad bridge as their final task. This example was chosen to be consistent with the pasta tower building activity. Figure 5 shows a basic block diagram of the game user flow experience. We will briefly discuss each block of the user flow experience.

\section{Overview}

This section of the game defines the goal of the game, which is to teach the engineering design process. It also brings out the need for the design process by presenting examples of failed bridges. In the overview, the students are introduced to basic construction materials like the beams and joints required to build their structure.

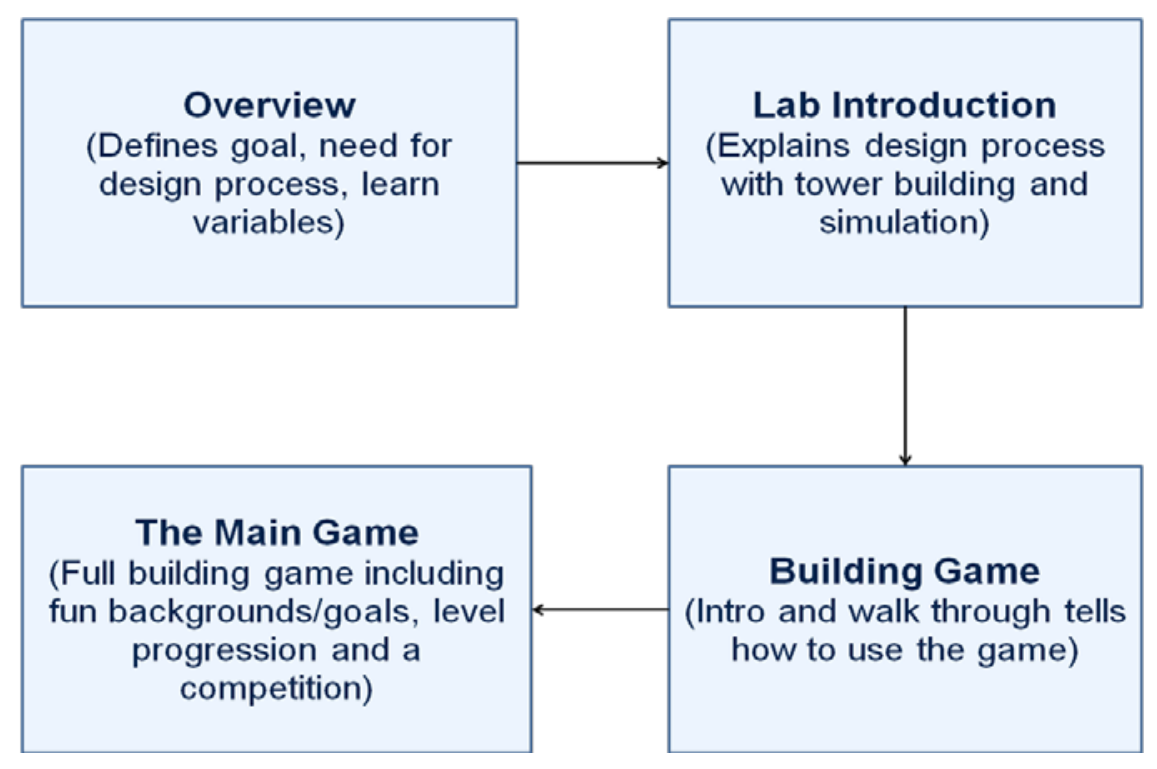

Figure 5. Serious Game User flow experience

\section{Lab Introduction}

In a lab section, students review in detail each of the core engineering design process steps. Once they learn these steps, the student have a chance to design a structure and make decisions that affect the weight, cost and load capacity of their structure. This was done by selecting predefined shape structures and different material, beam and joint choices. The game simulates their tower and shows the estimated load that their structure can withstand. A screen shot of lab introduction is shown in Figure 6. 


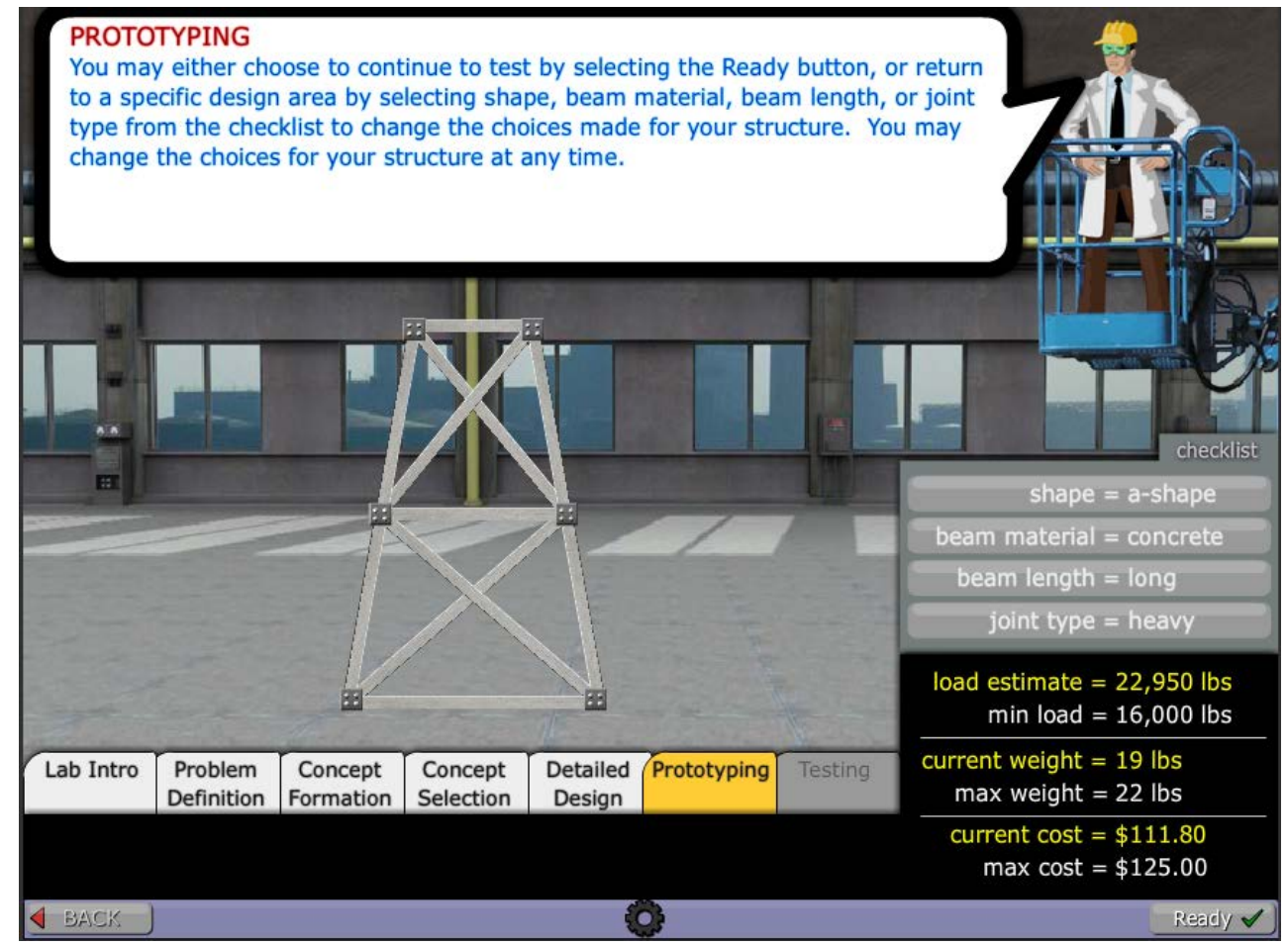

Figure 6. Screen shot lab introduction

\section{The Building Game}

In this part of the game, the student are guided on how to use the tools and screen areas to design, build and test a structure from scratch. It is similar to a tutorial; they have to join the dots and learn how to build their structure and use the tools to test their structure. Several tool tips are used to convey the message to the students. We have different goals for the students in this building game level. A screen shot of the building game level is shown in Figure 7.

\section{The Main Game}

The main game consists of three levels. The first level is a simple test tower, where the students are given some constraints on weight, cost and load to build their tower. The second level is a water tower level, where they have to build a tower to hold the water tank at the top of their tower. The third level is a train bridge level, where the students have to build a structure to support a train bridge. The difficulty of the level increases as the student's progress through different levels. The game also allots a score for each finished level as a measure of students' performance. A screen shot of the water and the train bridge level is shown in Figure 8. 


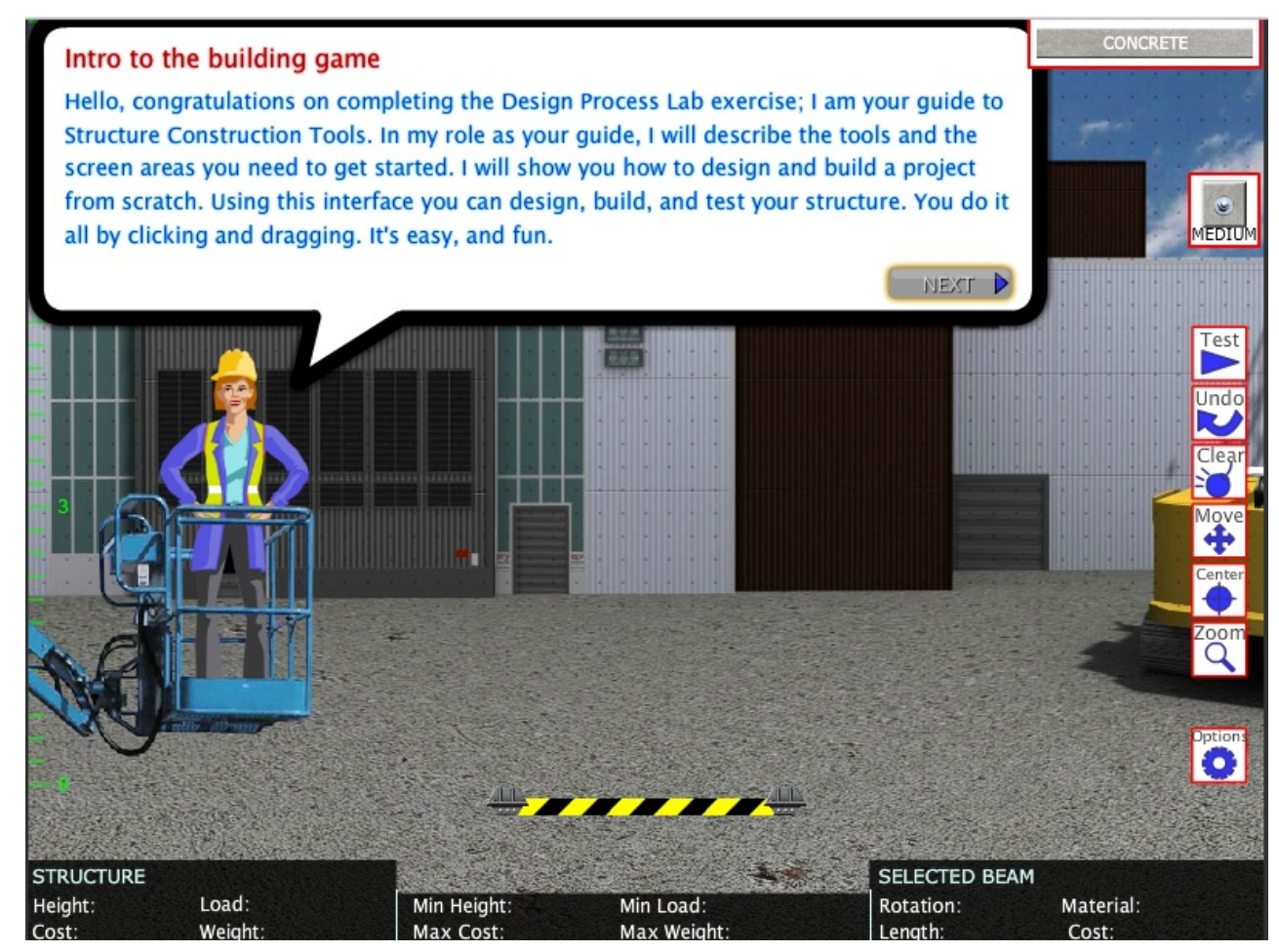

Figure 7. Screen shot of the building game level

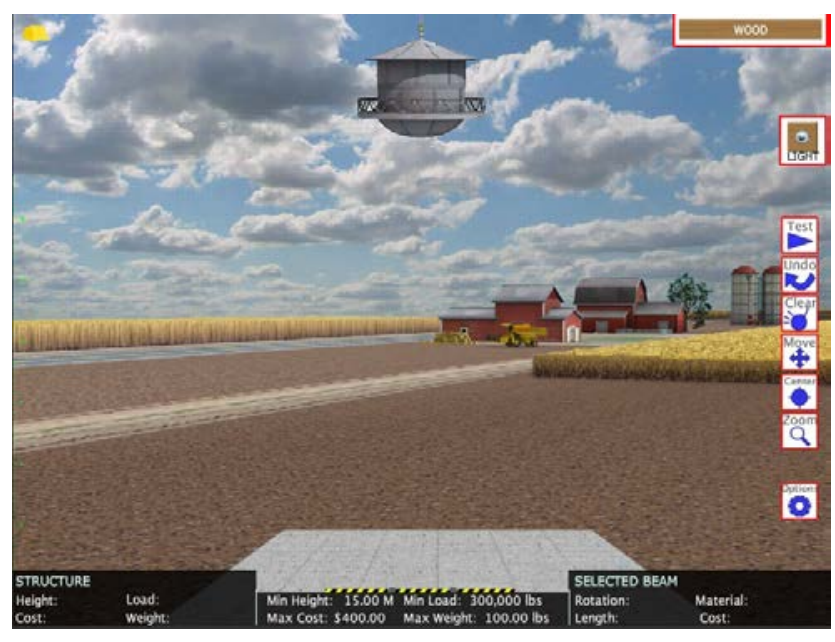

Water bridge level

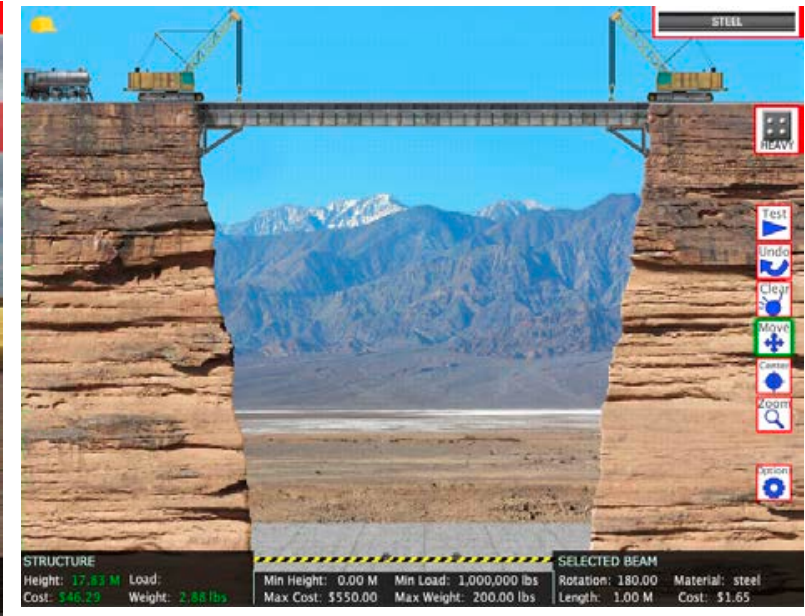

Train bridge level

Figure 8. A screen shot of the water bridge (left) and the train bridge (right) levels 


\section{$\underline{\text { Evaluation }}$}

Earlier researchers have shown that personal factors and characteristics can influence a students' approach to learning and learning outcomes. ${ }^{12,13,14,15}$ The $4 \mathrm{P}$ model was first used by Sankar et al. ${ }^{16}$ (2010) and is derived by studying the learning approach models used by Biggs and Moore ${ }^{14}$ (1992) and Nemanich et al (2009). ${ }^{17}$ It proposes that the presage conditions, along with learning modules (pedagogy factor), combine to create the approach a student takes in their learning (process factors), which in turn influences the improvement in achieving outcomes (product factors). In simple terms, it means that for different learning modules or instructional methods used to teach engineering design process concepts, the improvement in achieving outcomes may be different based on the presage and process factors. Figure 9 shows the $4 \mathrm{P}$ model with learning modules being the moderating variable.

$\begin{array}{llll}\text { Presage } & \text { Pedagogy } & \text { Process } & \text { Product }\end{array}$

Improvement in achieving outcomes

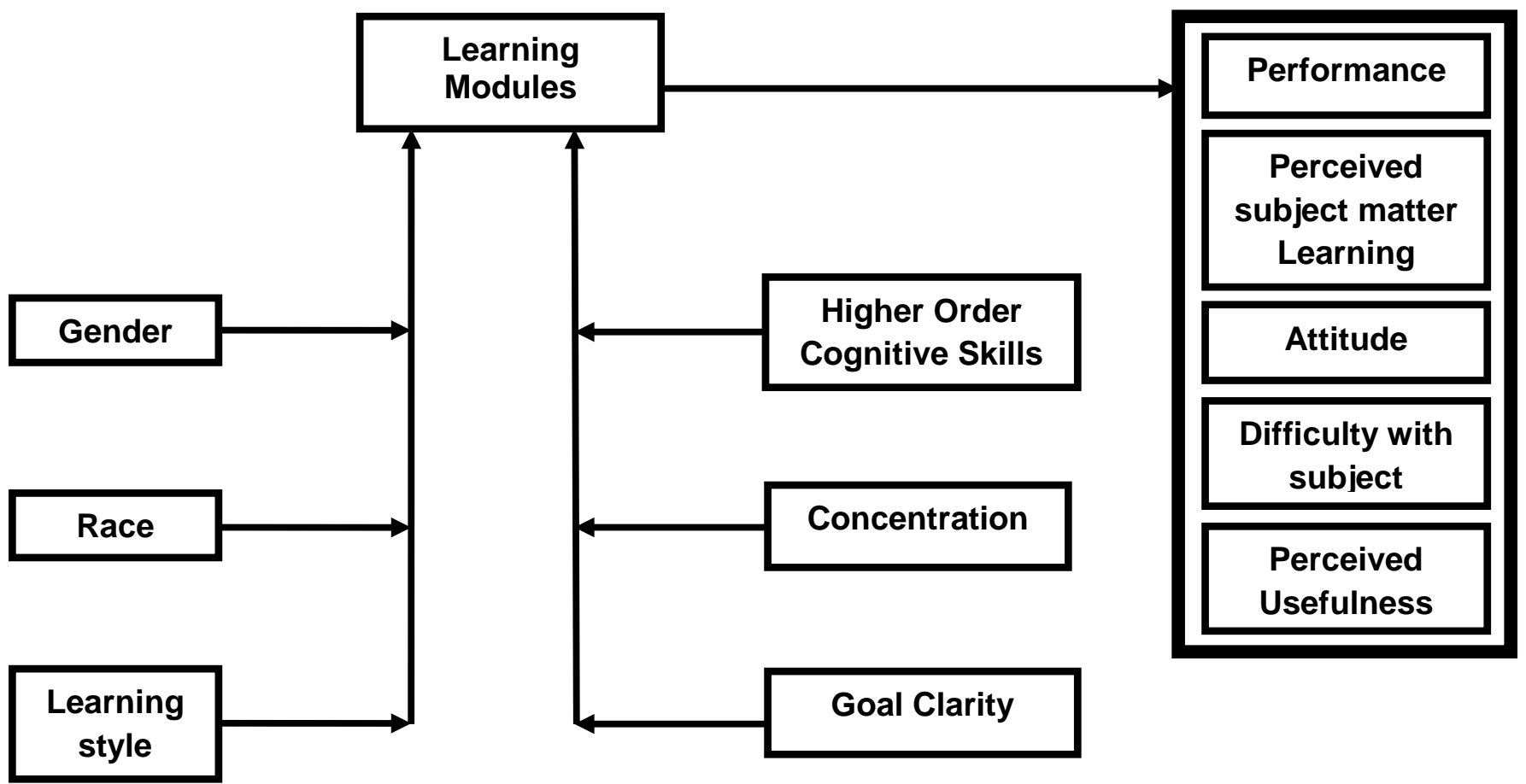

Figure 9. 4P model with learning modules as the moderating variable 


\section{$\underline{\text { Presage }}$}

Presage factors are factors that exist prior to the engagement and that affect the learning process. The presage factors considered in this model are gender, race and learning style. These factors interact with the learning module to affect the process and the learning outcomes. The presage factors usually constitute the independent variables in the 4P model

\section{Pedagogy}

The two learning modules used to teach the engineering design process are:

Engineering Design Learning Module 1 (EDLM 1)-includes a lecture on the engineering design process, an active learning exercise titled " Statistics Applied to Data Analysis," and a pasta tower building activity where the students follow the engineering design process to build a tower using pasta and masking tape.

Engineering Design Learning Module 2 (EDLM 2)-includes a lecture on the engineering design process, a design simulation game titled "Engineering Heights : The Design Process in Action," and a pasta tower building activity where the students follow the engineering design process to build a tower using pasta and masking tape.

The control section uses EDLM 1 and the experimental section uses EDLM 2.

\section{Process}

The heart of the teaching/learning system is at the process level, where the learning-related activity produces or does not produce the desired outcomes. ${ }^{18}$ Process incorporates the students' learning experience. ${ }^{17}$ The three process variables used in this model are higher order cognitive skills, concentration and goal clarity.

\section{$\underline{\text { Product }}$}

Product is the outcome of learning. Product factors are indicators of knowledge, skills and behaviors students gained by participating in the learning process. We have identified five product factors in the research model.

\section{Sample}

This serious game was implemented at Auburn University and at Hampton University. Students in the Introduction to Engineering courses at both universities were asked to participate by their instructors, and consent forms were signed by students and collected prior to all data collection. The entire study took place over the course of the fall 2012 semester at both schools. At Auburn University, three sections of the course were used to implement EDLM 2, and three sections of the course were control groups, where a non-engineering task was used to replace the serious game. Specifically, the students in the control sections were engaged in a statistics activity. At Hampton University, there were only two sections of the course available for this study, and one section was used to implement the EDLM 2, while the other course engaged in the statistics activity. 


\section{Data Analysis}

Data was collected using multiple sources, both subjective (e.g., survey instruments) and objective (e.g., project and test grades). At the beginning of each survey instrument, students entered a four digit identification code that was created and distributed by the course instructor. The code was used during data analysis to match multiple surveys and course grades from respondents. The resulting data allowed the evaluation team to conduct the analyses required to test the relationships in the $4 \mathrm{P}$ model. We conducted both qualitative and quantitative analysis to find out the effectiveness of the serious game. The detailed quantitative analysis results will be discussed in the journal paper titled "Teaching Engineering Design Principles through a Serious Game," and we are planning to submit this to the Computers in Education(CoED) journal. Some preliminary qualitative results are presented here.

\section{$\underline{\text { Results }}$}

Students learned about the engineering design process from the serious game. One student said the serious game modeled, "how you have to have a bunch of different ideas and decide which works best for the task." For another, the choice of material for each scenario was a new concept he learned. Several students appreciated having cost limits. One said, "I liked how you have a price range because in the real world, there's not an endless supply of money.” Another student learned the value of the "planning process." It was better to plan your structure and carefully build, than to rush through it and make mistakes that you would have to repair. Another student built on this idea when he said, "In the real world, you probably won't get a second chance to build that bridge."

A student explained, "this computer simulation is a good idea in the sense that it's a game. For engineering types, it's a good concept." Another student said, "these tools build conceptual understanding. I don't know why it works, but I understand there's too much [stress] here.” Other students agreed the CSA would make for a, "great study tool."

Some students indicated that the serious game was fun and enjoyable. For many, it was preferable to learning via other methods, such as lecture and textbook reading. While many said their preference was for off-computer, hands-on activities, they appreciated the experience for its teaching of the engineering design process, principles of building structures, and provision of realistic parameters. Several students felt it was appropriate as a complement to the traditional classroom activities (e.g., reading, lecture, labs), but not as a replacement.

\section{Summary and Findings}

Based on the initial feedback of the students, the students seem to like the serious game. We found that students who participated in the serious game prior to building their pasta tower performed at a higher level than students who did not participate in the serious game.

In summary, all of the significant findings in this study revealed greater gains in both objective and subjective measures for students who participated in the serious game. Moving forward, the continuation of this research will allow the refinement of our 4P model to include constructs 
based on a combination of these quantitative data and analysis of the qualitative data provided via focus groups

\section{Acknowledgement}

We thank our industrial partners, Toolwire Inc. for working with us in providing the necessary technical help in developing this serious game. We particularly thank Dayvid Jones and Michael Watkins and their team in helping us in the design and development of this serious game. This project was funded by the National Science Foundation, IIP \#1110223. The PI of the project was Steve Lynch from Toolwire Inc. and Co-PI Dr. P. K .Raju from Auburn University. Any opinions, findings, and conclusions or recommendations expressed in this paper are those of the authors and do not necessarily reflect the views of the National Science Foundation.

\section{References}

1. Games for Scientific and Engineering Education ( 2007). Communications of the ACM, 50(7)

2. Dabbagh, N., \& Menasce, D.A. (2006). Student perceptions of engineering entrepreneurship: An explanatory study. Journal of Engineering Education.

3. Raytheon Company. Retrieved from http://investor.raytheon.com/phoenix.zhtml?c=84193\&p=irolnewsArticle\&ID=1631503\&highlight=

4. Connolly, T. M., Boyle, E. A., MacArthur, E., Hainey, T., Boyle, J. M. (2012). A systematic literature review of empirical evidence on computer games and serious games. Computers \& Education, 59(2),661-686

5. Dym, C., Agogino, A., Eris, O., Frey, D., \& Leifer, L. (2005). Engineering design thinking, teaching, and learning.

6. Shaha, S. H. (1998). Integrated outcomes: Where CIOs need to be thinking. Health Management Technology, 19(10), 44

7. Vazsonyi, A. (1999). Which door has the Cadillac. Decision Line, 30(1), 17-19

8. Abt, C. C. Serious Games. Lanham (1987), Serious games-Reprint.New York: Viking Press

9. Prensky, M. (2001). Digital game-based learning. New York, NY: McGraw-Hill

10. Hernandez, N. V., \& Rangel, G. D. (2010). Improving engineering design education: From skills to educational objectives. ASME.

11. Pahl, G., et al. (2007). Engineering design: A systematic approach. Springer.

12. Biggs, J. B. (1970). Personality correlates of certain dimensions of study behavior. Australian Journal of Psychology, 22(3), 287-297.

13.Biggs, J. B. (1987).Student approaches to learning and studying: Research monograph, Australian Council for Educational Research Ltd: Radford House.

14. Biggs, J. B. (1992). Why and how do Hong Kong students learn?: Using the learning and study process questionnaires. Faculty of Education, University of Hong Kong 
15. Dart, B. C., Burnett, P. C., Purdie, N., Boulton-Lewis, G., Campbell, J., \& Smith, D. (2000). Students' conceptions of learning, the classroom environment, and approaches to learning. The Journal of Educational Research, 93(4), 262-270.

16. Sankar, C. S., \& Clayton, H. (2010). An Evaluation of use of multimedia case studies to improve an introduction to information technology course. International Journal of Information and Communication Technology Education (IJICTE), 6(3), 25-37.

17. Nemanich, L, Banks, M, \& Vera, D. (2009). Enhancing knowledge transfer in classroom versus online settings: The interplay among instructor, student content and context, Decision Sciences Journal of Innovative Education, $7(1), 123-148$

18. Biggs, J.B., Kember, D., \& Leung, D.Y.P. (2001) The revised two factor study process questionnaire: R-SPQ2F. British Journal of Educational Psychology. 71, 133-149 